\title{
Expansão urbana sobre compartimentos de relevo suscetíveis à inundação: Zona Sul do município de Porto Alegre, Rio Grande do Sul
}

\author{
Nina Simone Vilaverde MOURA ${ }^{1}$, Emilio Federico MORAN ${ }^{2}$, Tielle Soares DIAS ${ }^{3}$, Giselle PARIS ${ }^{4}$ \\ \& Fabiana Ferreira BORGES ${ }^{4}$
}

(1) Departamento de Geografia, Programa de Pós-graduação em Geografia, Instituto de Geociências, Universidade Federal do Rio Grande do Sul. Av. Bento Gonçalves, 9500, CEP 91.540-000, Porto Alegre, RS. E-mail: nina.moura@ufrgs.br.

(2) Center for Global Change and Earth Observations and Department of Geography, Michigan State University. 1405 South Harrison road, Room 218, East Lansing, MI 8823, USA. E-mail: moranef@msu.edu.

(3) Programa de Pós-graduação em Geografia, Instituto de Geociências, Universidade Federal do Rio Grande do Sul. Av. Bento Gonçalves, 9500, CEP 91.540-000, Porto Alegre, RS. E-mail: tiellesdias@yahoo.com.br.

(4) Departamento de Geografia, Instituto de Geociências, Universidade Federal do Rio Grande do Sul. Av. Bento Gonçalves, 9500, CEP 91.540-000, Porto Alegre, RS. E-mail: gi.pa@terra.com.br, fabiferbor@gmail.com.

Recebido em 06/2015. Aceito para publicação em 07/2016.

Versão online publicada em 26/08/2016 (www.pesquisasemgeociencias.ufrgs.br)

\begin{abstract}
Resumo - A zona sul do município de Porto Alegre (RS) é uma área de expansão urbana relativamente recente. Esse crescimento provoca alterações na dinâmica ambiental que, ocorrendo de maneira não planejada, pode acarretar em situações de perigo para seus ocupantes. Diante isso, esse artigo visou à elaboração de alguns indicadores ambientais para um adequado ordenamento ambiental da bacia hidrográfica do Arroio do Salso, zona sul de Porto Alegre. Esse artigo tem o intuito de apresentar os resultados obtidos a partir dos seguintes objetivos: (1) caracterizar as áreas suscetíveis à inundação na bacia hidrográfica; (2) analisar a dinâmica pluviométrica no município; e, (3) analisar a cobertura vegetal, o uso da terra e as condições socioeconômicas e de infraestrutura da população residente na bacia hidrográfica do Arroio do Salso. Para tanto, foi elaborado um mapa de suscetibilidade à inundação e analisadas as formas de ocupação e as características socioeconômica e de infraestrutura da população na referida bacia. Além disso, foram levantados dados pluviométricos anuais, mensais e diários e coletadas amostrais de sedimentos superficiais, para análise granulométrica nos diferentes setores suscetíveis à inundação. A partir das análises realizadas, pode-se concluir que são bastante comuns os eventos capazes de gerar inundações e/ou alagamentos na bacia hidrográfica do Arroio do Salso e em vários pontos do município de Porto Alegre. Os efeitos da concentração e da densidade urbana, a desigualdade nas condições de infraestrutura dos moradores do espaço urbano e as irregularidades urbanísticas aumentam a suscetibilidade aos processos de inundação em áreas com potencial natural ao referido processo.
\end{abstract}

Palavras-chave: inundação urbana, ambiente urbano, Arroio do Salso, Porto Alegre.

\begin{abstract}
URBAN EXPANSION ON RELIEF COMPARTMENTS SUSCEPTIBLE TO FLOODING: SOUTH ZONE OF THE CITY of PoRTo ALEGRE, Rio Grande Do Sul. The southern area of Porto Alegre municipality (RS) has only recently experienced urban growth. This urban expansion causes changes in the environmental dynamics which can lead to situations of high risk to its occupants. Therefore, this article has aimed the elaboration of some environmental indicators for an appropriate spatial and environmental planning for the Arroio do Salso's watershed, southern area of Porto Alegre. This article has the purpose to present the results from research guided by the following objectives: (1) to characterize the flooding susceptible areas in the watershed, (2) to analyze the dynamic of rain the city of Porto Alegre; and, (3) to analyze the vegetation cover, land use and socio-economic and infrastructure conditions of the resident population in the study area. For this purpose, we constructed a map of susceptibility to flooding and analyzed the forms of occupation and socioeconomic characteristics of the population and infrastructure in that area. Additionally, rainfall data were collected annually, monthly and daily and we collected sediment samples for granulometric analysis in different sectors susceptible to flooding. From the analysis, one can conclude that flood related events are quite common in various locations of the municipality. The effects of concentration and urban density, the inequality of infrastructure to the residents of urban space and urban irregularities in housing location increase the susceptibility to flooding processes in areas with natural potential to that event.
\end{abstract}

Key-words: urban flooding, urban environment, Arroio do Salso, Porto Alegre. 


\section{Introdução}

0 presente trabalho está relacionado às atividades realizadas no projeto de pesquisa denominado Indicadores Ambientais para o Ordenamento Territorial da Bacia Hidrográfica do Arroio do Salso que teve como proposta a elaboração de indicadores ambientais sobre a referida bacia hidrográfica localizada na zona sul do município de Porto Alegre, no estado do Rio Grande do Sul. Ao longo do desenvolvimento do projeto contribuições foram sendo publicadas, com resultados obtidos em diferentes temáticas (Burkt \& Fujimoto, 2009; Basso \& Pizzato, 2011; Moura et al., 2013). Apesar de pouco ocupada, a área representa um dos mais recentes focos de ocupação e de especulação imobiliária no município, em virtude do esgotamento de outras áreas e também das novas propostas do Plano Diretor de Desenvolvimento Urbano e Ambiental ( 2 o PDDUA, Lei $\mathrm{n}$-434-99) que redefiniu a área rural da cidade, permitindo o direcionamento do crescimento urbano para a zona sul.

0 adensamento populacional e a impermeabilização crescente do solo condicionam impactos negativos ao ambiente, destacando-se, entre outros, a intensificação dos processos de inundação urbana; alteração no escoamento devido ao aumento da produção de sedimentos; degradação da qualidade da água pelos esgotos pluviais e/ou cloacais e contaminação dos aquíferos.

A zona sul do município de Porto Alegre é uma área de especulação de empreendedores pelas suas amenidades naturais, que incorporadas às amenidades construídas, nos loteamentos e condomínios, são, nas últimas décadas, de grande interesse imobiliário. Esse processo de expansão urbana provoca alterações na dinâmica natural do meio físico, que ocorrendo de maneira desordenada e não planejada, podem acarretar em situações de perigo para seus ocupantes, especialmente relacionados aos eventos de inundação em função das suas características geológicas, geomorfológicas e pedológicas, entre outras.

Entende-se que uma análise dos indicadores ambientais diante do processo de urbanização que avança sobre essas áreas poderá fornecer informações que permitam a adoção de medidas de prevenção ou redução dos eventos de inundação e de outros problemas ambientais, como por exemplo, a degradação da qualidade das águas pelos esgotos pluviais e ou cloacais e a contaminação dos aquíferos.

Nesse sentido, esse artigo tem o objetivo de apresentar os resultados obtidos, nas últimas etapas de realização do projeto de pesquisa, como:
(1) a identificação das áreas suscetíveis à inundação na bacia hidrográfica; (2) a análise da dinâmica pluviométrica no município de Porto Alegre; e, (3) a caracterização da cobertura vegetal, o uso da terra e as condições socioeconômicas e de infraestrutura da população residente na área de estudo.

\section{2 Área, materiais e métodos}

\section{1 Área de estudo}

A bacia hidrográfica do Arroio do Salso se localiza na zona sul do município de Porto Alegre com uma área de $92,94 \mathrm{~km}^{2}$ é a maior bacia hidrográfica do município e, quase a totalidade da área da bacia, de acordo com o Plano Diretor de Desenvolvimento Urbano Ambiental de Porto Alegre, encontra-se nas macrozonas denominadas de Restinga e Cidade Rururbana, sendo, essa última, o atual alvo de grande especulação imobiliária do município (Fig. 1).

\subsection{Pressupostos teóricos e metodológicos}

As enchentes e inundações são fenômenos que atingem com frequência áreas ocupadas, ocasionando, muitas vezes, perdas para a população atingida. No entanto, são fenômenos de natureza hidrometeorológica que fazem parte da dinâmica natural ocorrendo com periodicidade nos cursos d'água, independente da ocupação ou não da bacia hidrográfica, e frequentemente deflagrados por chuvas fortes e rápidas ou chuvas de longa duração (Tominaga et al., 2012). As inundações e enchentes são eventos geoambientais de natureza atmosférica, hidrológica ou oceanográfica. Esses eventos estão relacionados à precipitação atmosférica, conforme sua quantidade e intensidade, mas também ao escoamento superficial e subsuperficial sendo, portanto, a permeabilidade do solo, o grau de saturação e as características morfométricas e morfológicas da bacia de drenagem, suas condicionantes. Em condições naturais as planícies e fundos de vales estreitos apresentam lento escoamento superficial das águas das chuvas (Tominaga et al., 2012).

Esses episódios são intensificados pelas alterações ambientais e intervenções urbanas produzidas pelo homem, tais com o a impermeabilização do solo, retificação dos cursos d'água e redução no escoamento dos canais devido a obras, ou por assoreamento. Assim é nas cidades onde se concentram os problemas decorrentes de enchentes e inundações, devido principalmente ao modelo de urbanização, com ocupação de planícies e im- 


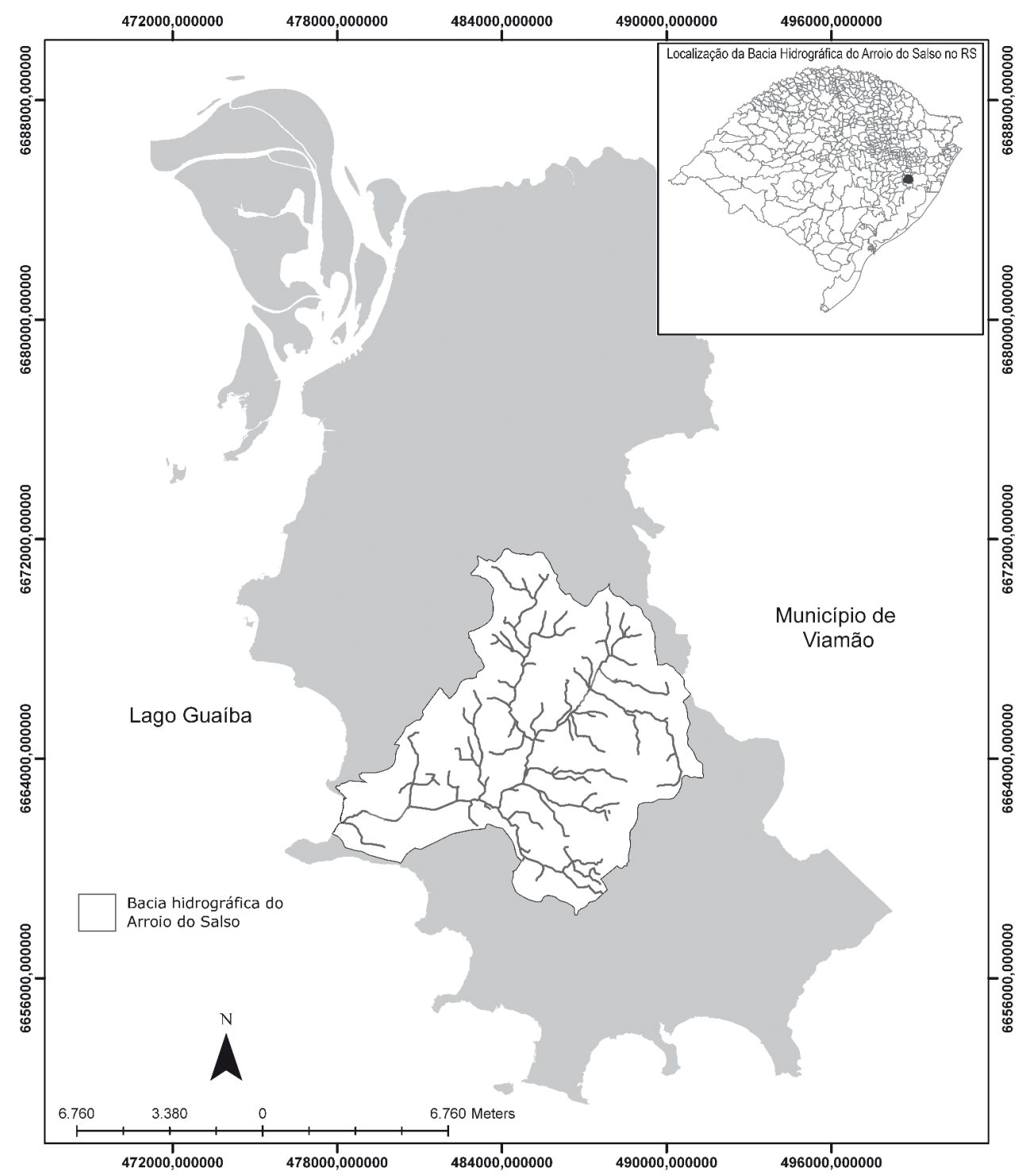

Figura 1. Localização da bacia hidrográfica do Arroio do Salso no município de Porto Alegre, RS.

permeabilização ao longo das vertentes (BRASIL, 2007).

Em termos conceituais, enchentes ou cheias é a denominação para os fenômenos deflagrados pelas águas da chuva, quando ao alcançarem um curso d'água, causam acréscimo na descarga d'água por certo período de tempo. Em alguns casos, durante a enchente, as vazões aumentam de forma que a calha do curso d'água não tem capacidade de descarga, ocorrendo o extravasamento para as áreas marginais, normalmente não ocupadas pelas águas. Este extravasamento caracteriza uma inundação, e a área marginal, que periodicamente recebe esses excessos de água, denomina-se planície de inundação, várzea ou leito maior (BRASIL, 2007).

Dentre os fatores que condicionam a ocorrência de enchentes e inundações podem ser citados os naturais, climáticos e geomorfológicos, de um dado local; e condicionantes relacionados às intervenções antrópicas no meio físico. Os principais condicionantes naturais, segundo Tominaga et al. (2012), são: formas do relevo; características da rede de drenagem da bacia hidrográfica; intensidade, quantidade, distribuição e frequência das chuvas; características do solo e o teor de umidade e presença ou ausência da cobertura vegetal.

Os fatores elencados permitem a compreensão da dinâmica dos eventos de enchentes e inundações desde a precipitação pluviométrica até sua relação com o solo. A vazão da água será influenciada pelas formas do relevo, pelo padrão de drenagem estabelecido e a capacidade de infiltração da superfície, possibilitando que, em decorrência dos ajustes entre esses fatores, ocorram enchentes e inundações no local.

Os condicionantes relacionados às intervenções antrópicas elencados por Tominaga et al. (2012) são: uso e ocupação irregular nas planícies e margens de cursos d'água; disposição irregular de lixo nas proximidades dos cursos d'água; alterações nas características da bacia hidrográfica e dos 
cursos d'água (vazão, retificação e canalização de cursos d'água, impermeabilização do solo, entre outras); intenso processo de erosão dos solos e de assoreamento dos cursos d'água.

A ocupação e a crescente expansão das áreas urbanas modificam, criam e destroem estruturas naturais anteriormente constituídas e em equilíbrio com todo o sistema. Essas intervenções nos municípios implicam de forma geral, na retificação, canalização ou tamponamento dos cursos d'água, eliminando meandros, facilitando as construções nessas áreas e acelerando a vazão. Associado a isso, nas áreas urbanas é verificada a impermeabilização do leito maior e a modificação nos perfis das vertentes do entorno. Tudo isso ocasiona a aceleração dos escoamentos, o aumento consideravelmente dos picos de vazão e, em muitos casos, as inundações (Moura et al., 2013).

Diante do crescimento da exposição de cidades aos fenômenos naturais, causadores de danos, entre outros a inundação, não é possível apresentar como causa apenas as variáveis, dentre as anteriormente mencionadas. É preciso, também, analisar a vulnerabilidade dos citadinos, das construções, da infraestrutura e do sistema institucional e/ou político local, devido ao fato de serem principalmente essas as variáveis que fazem com que exista maior ou menor grau de perda diante desses eventos. Assim, destacam-se as considerações de Castells (2000) sobre a necessidade de articular as questões naturais e as práticas sociais, pois os danos não ocorrem de forma igualitária. Para analisá-los deve-se considerar a realidade social. Dessa forma, pode-se explicar melhor por quais razões determinados eventos afetam algumas parcelas da população e não outras.

O sistema político municipal, no qual está concentrada a gestão urbana, funciona como o causador de efeitos perversos através da frágil aplicação do código de urbanismo, ou sua inexistência, do custo proibitivo da terra, do desvio do sistema fiscal, mas também do clientelismo e da corrupção política.

Segundo Tucci (2007), para que essas ações realmente apresentem resultados é preciso reconhecer que embora esporádico, o impacto sobre a sociedade é alto, tanto em aspectos econômicos quanto sociais; as causas estão na ocupação dos espaços antes tomados pelas águas e para isso existe necessidade de informação da sociedade sobre o problema, incluindo a população e os gestores, pois as inundações em áreas urbanas é um tema transversal, devendo extrapolar as divisões administrativas. 0 sucesso dessas medidas, por serem de longo prazo, envolvem também a cobrança dos investimentos públicos e o conhecimento sobre o tema.

Em Porto Alegre são verificadas tentativas de avanço em relação ao manejo das águas pluviais e cloacais, através da consolidação do Plano Diretor de Drenagem Urbana e do Plano Diretor de Esgotos (DEP, 2005), respectivamente, pois reforçam a busca por uma gestão sustentada de longo prazo. No entanto, observa-se a expansão urbana, de forma espontânea, sobre áreas suscetíveis à inundação, sem que o governo municipal intervenha para impedir esse tipo de ocupação.

\subsection{Procedimentos metodológicos e operacionais}

A análise e o mapeamento das áreas suscetíveis à inundação da Bacia Hidrográfica do Arroio do Salso foram elaborados e, inicialmente publicados em Fujimoto \& Dias (2010) e Moura et al. (2013). Nesses momentos, a área suscetível à inundação foi dividida em quatro categorias de suscetibilidade através das características distintas de cada uma como: altitude, declividade, tipos e formas de relevo, características do solo, proximidade de corpos d'água, etc. As quatro categorias foram classificadas como muito alta, alta, média e baixa e, posteriormente a essa classificação e caracterização, para cada uma dessas áreas foram selecionados pontos para coleta amostral de material de cobertura superficial, a fim de obter dados sobre a textura dos sedimentos que permitissem corroborar ou reformular as categorias identificadas.

As amostras de material de cobertura superficial foram coletadas em campo a cerca de $50 \mathrm{~cm}$ de profundidade ou após eliminação de resíduos vegetais dos horizontes superficiais, através de trincheiras, tendo sido posteriormente acondicionadas em sacos plásticos e levadas até o Laboratório de Sedimentologia do Centro de Estudos de Geologia Costeira e Oceânica (CECO) da Universidade Federal do Rio Grande do Sul (UFRGS) para a análise granulométrica. Para sua realização foram utilizados dois processos: (1) para os sedimentos grossos a análise foi realizada pela técnica de peneiramento com peneiras de tamanho de $16 \mathrm{~mm}$ até $0,62 \mathrm{~mm}$ de acordo com a Escala de Wenthworth; e, (2) para os finos (silte e argila) foi aplicado o processo hidráulico de sedimentação baseado na Lei de Stokes. Estes processos possibilitam caracterizar a estrutura do material de cobertura superficial (textura, permeabilidade, porosidade, entre outros) complementando a análise da suscetibilidade aos processos de inundação.

0 índice pluviométrico é um fator importante nos estudos de áreas suscetíveis à inundação, pois 
permite avaliar os padrões de ocorrência e, neste sentido, auxiliar nos planos de ação tanto em situações de emergência quanto de prevenção. Para avaliação da precipitação foram utilizados dados da estação meteorológicas de Porto Alegre do INMET - 8 ${ }^{\circ}$ DISME (Instituto Nacional de Meteorologia - 8o Distrito de Meteorologia). 0 total diário de precipitação da estação do INMET corresponde à soma das leituras das $18 \mathrm{~h} 00 \mathrm{~min}$ UTC do dia anterior à observação, até às $12 \mathrm{~h}$ UTC do dia informado (BRASIL, 1999). Os dados foram obtidos a partir do BDMEP - Banco de Dados Meteorológicos para Ensino e Pesquisa (INMET, 2013). São informações diárias que foram analisadas desde o ano de 1970 até o ano de 2012 (último ano cuja série era completa). Os meses nos quais havia alguma falha no registro foram complementados com os relatórios fornecidos pelo Laboratório de Geografia Física do Departamento de Geografia da UFRGS, obtidos diretamente do $8^{\circ}$ DISME. Os dados foram organizados em tabelas e gráficos para proporcionar uma análise da distribuição anual, mensal e, por vezes, diária das precipitações.

O mapeamento da Cobertura Vegetal e Uso da Terra foi realizado a partir do Diagnóstico Ambiental de Porto Alegre (Hasenack, 2008), adaptado aos objetivos dessa pesquisa e com informações atualizadas obtidas através do Google Earth e trabalhos de campo nos anos de 2010 a 2012. Para tanto, a cobertura vegetal foi classificada de acordo com o porte e a densidade vegetal e, com isso, indicando sua proteção aos processos de erosão pluvial e de escoamento superficial e a capacidade de infiltração e de escoamento subsuperficial. A legenda do mapa foi organizada em onze (11) categorias, que são: (1) cobertura vegetal, subdividida em: vegetação arbórea, vegetação arbustiva, vegetação herbácea e cultivo; (2) edificações: ocupação urbana concentrada, ocupação urbana dispersa, edificações rurais diversas; (3) áreas não edificadas: solo exposto, afloramento rochoso e vias; e (4) água: corpos e cursos d'água.

O Mapa de Cobertura Vegetal e Uso da Terra e a análise das características socioeconômicas da população e de infraestrutura dos domicílios indicam as moradias mais suscetíveis aos eventos de inundação. A partir da identificação das áreas edificadas localizadas dentro da área potencialmente inundável foram feitos levantamento dos setores censitários representativos de cada tipologia de edificação identificada (cada setor censitário possui entre 200 a 250 moradias), obtidas do Censo Demográficas do IBGE de 2004. Para tanto, foram selecionados 15 setores cujos dados extraídos foram organizados em tabelas. As informações cen- sitárias procuraram caracterizar o perfil socioeconômico da população (nível de escolaridade, renda média e número de banheiros por domicílio) e de infraestrutura dos domicílios (abastecimento de água, esgoto cloacal e coleta de lixo) que, pelo detalhe dos dados, proporcionou obter uma caracterização mais precisa das moradias em situação de legalidade e de irregularidade fundiária (ocupação irregular). A partir dessas informações, indicaram-se áreas mais suscetíveis para a ocupação urbana na bacia hidrográfica em relação aos eventos de inundação.

Além disso, foram realizadas saídas de campo para a avaliação da representatividade dos setores censitários escolhidos, bem como entrevistas e observações sobre o comportamento do Arroio do Salso em períodos de alta pluviosidade, em especial os eventos do segundo semestre de 2009 e de 2012.

\section{Resultados e discussão}

\subsection{Caracterização das áreas suscetíveis à inunda- ção na bacia hidrográfica do Arroio do Salso}

A análise e o mapeamento das áreas suscetíveis à inundação foram inicialmente publicados em Fujimoto \& Dias (2010) e Moura et al. (2013), referentes às áreas de planícies e/ou formas de relevo cujos processos agradacionais são predominantes na sua formação, dentro da área da referida bacia hidrográfica. Nesse artigo são apresentados a caracterização realizada anteriormente e os resultados das análises do material de cobertura superficial obtidos após a classificação. Os resultados das análises granulométricas fortaleceram a classificação realizada e, com isso, as classes identificadas apresentam as seguintes características (Fig. 2).

As áreas com muito alta suscetibilidade à inundação são aquelas que apresentam as menores altitudes (menores de $5 \mathrm{~m}$ ) associadas com as declividades mais baixas e estão representadas por grande extensão de terras ao longo do trecho inferior do Arroio do Salso. As análises granulométricas realizadas neste setor, conforme demonstra a figura 3, indicam predominância de frações mais finas como argila e silte. A presença de sedimentos mais grossos é quase inexistente, confirmando assim a altíssima suscetibilidade à inundação, pois se trata de uma área plana, pouco drenada, onde predomina a deposição de sedimentos. Com isso, apresentam processos de escoamento pouco atuantes. 


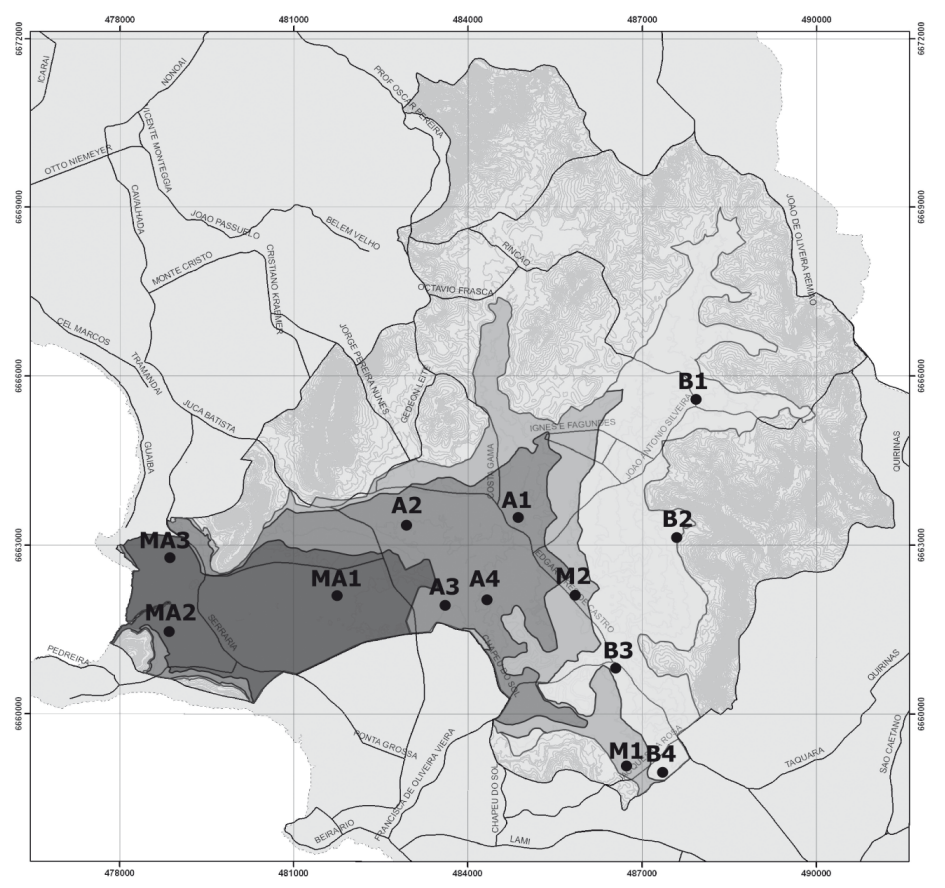

LEGENDA

SUSCETIBIUDADE À INUNDACÃO



Pontos de Coleta

- Muito Alta (MA)

- Alta (A)

- Média (M)

- Baixa (B)



Figura 2. Mapa de suscetibilidade à inundação e pontos de coleta de sedimentos superficiais.

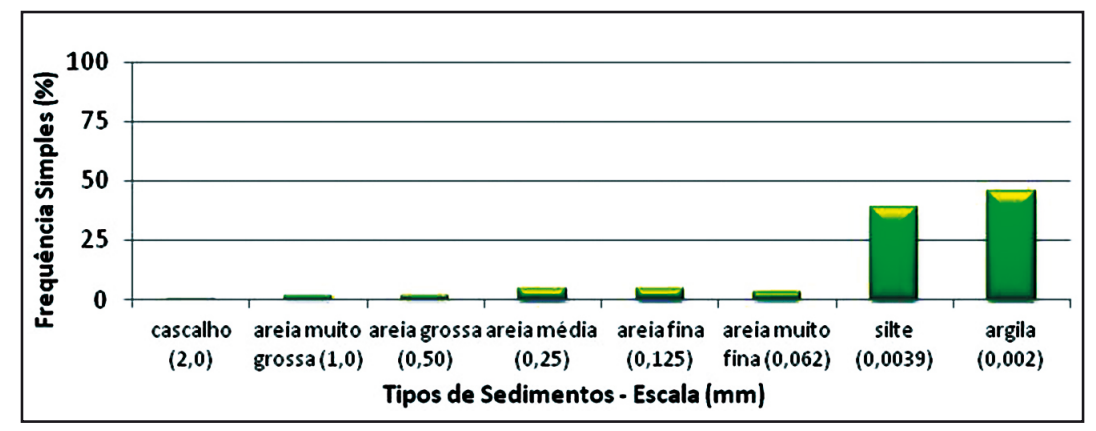

Figura 3. Distribuição granulométrica da amostra obtida no compartimento de suscetibilidade muito alta à inundação (MA1).

As áreas consideradas com alta suscetibilida$d e$ apresentam altitudes entre 5 e $15 \mathrm{~m}$ e solos mal drenados, representadas pelo padrão em forma de planícies flúvio-lagunares e, secundariamente, pelo padrão em forma de patamares planos (Moura et al., 2013). A análise granulométrica indica uma grande concentração de silte e areia fina e uma diminuição de argila em relação à classe de muito alta suscetibilidade. Ainda assim, a predominância de sedimentos finos diminui a porosidade e, consequentemente, a infiltração, e dessa forma proporciona a concentração das águas e dos sedimentos em função das baixas declividades e altitudes do terreno.

As áreas de média suscetibilidade são caracterizadas por ser espacialmente reduzidas em relação às outras categorias (baixa, alta e muito alta) e possuem elevação entre 15 a $20 \mathrm{~m}$. A análise granulométrica revela uma quantidade considerável de areias grossa e média, ainda que a presença de finos permaneça significativa e, nesse sentido, os sedimentos são também caracterizados como mal a muito mal drenados, com tendência a retenção de água em períodos de intensa precipitação.

As áreas de baixa suscetibilidade são caracterizadas por terem uma maior elevação em relação aos outros setores inundáveis, com altitudes variando de 20 a $30 \mathrm{~m}$. Apresentam declividades de 2 a $5 \%$ e os padrões geomorfológicos abrangidos são as formas de planícies flúvio-lagunares, em patamares planos e em colinas isoladas, sendo essas colinas de formação sedimentar e de baixas altitudes (Moura et al., 2013). Os solos permanecem com as características de drenagem dificultada, sendo mal drenados. No entanto, as análises granulométricas (Fig. 4) revelam a presença de sedimentos como areia grossa e areia média, favorecendo os processos de infiltração e escoamento e, com isso, 
diminuindo a suscetibilidade à inundação, principalmente quando comparado aos demais setores

da bacia hidrográfica.

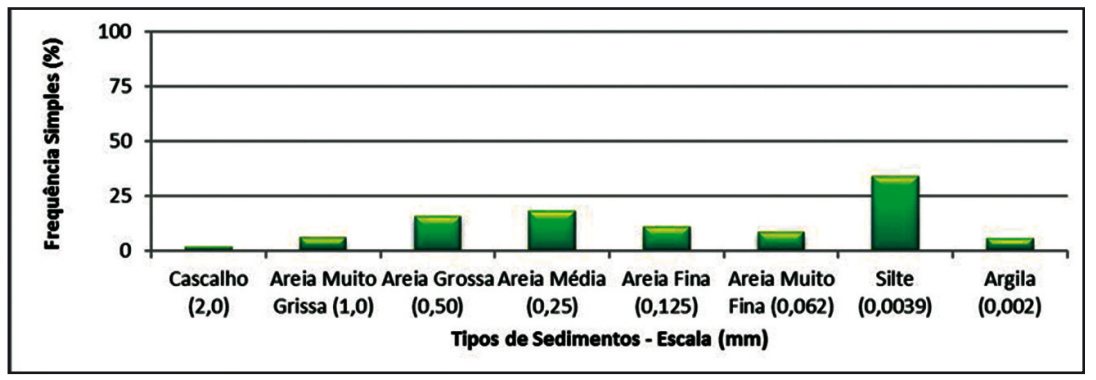

Figura 4. Distribuição granulométrica da amostra obtida no compartimento de baixa suscetibilidade à inundação (B4).

3.2 Análise pluviométrica na série histórica 1970 a 2012

Para a análise da dinâmica pluviométrica do município, foram utilizados os dados coletados no 8 Distrito de Meteorologia de Porto Alegre. O período da análise abrange o intervalo de 1970 a 2012, cobrindo valores de precipitação anuais, mensais e diárias. Além dos valores de precipitação, também foram analisados os dias chuvosos e os principais eventos de chuva em três anos que apresentaram os maiores índices pluviométricos entre os quarenta anos pesquisados, ou seja, os anos de 1972, 1987 e 2009. Tais anos estão relacionados à ocorrência do fenômeno El Niño com diferentes intensidades, ou seja, o ano de 1972 refere-se a um período de alta intensidade e os anos de 1987 e 2009 de moderada e fraca intensidade, respectivamente (CPTEC, 2014).

A média do volume de chuva anual na série analisada é de 1438,0 mm, no entanto verifica-se que em $44,2 \%$ dos períodos o total pluviométrico foi maior que $1500 \mathrm{~mm}$, superior à média. Os anos que tiveram os maiores totais pluviométricos foram selecionados e tiveram detalhados os totais pluviométricos mensais.

Baseado no período analisado, a média mensal de chuvas para Porto Alegre pode ser considerada de aproximadamente $120 \mathrm{~mm}$. Para o ano mais chuvoso da série, 1972, com total acumulado de 1983,6 mm, observa-se uma distribuição mensal das chuvas superior à média para a série em questão em 9 dos 12 meses do ano. A média mensal de precipitação para o ano de 1972 foi de 165,3 $\mathrm{mm}$. Os meses com maior volume de chuvas foram junho, agosto, setembro e janeiro e os com menor foram dezembro e maio (Fig. 5).

No ano de 1972 houve 116 dias chuvosos, considerando aqueles com ocorrência superior a 1 mm. Em março apesar de não ser o mês com maior total pluviométrico, choveu em 15 dias, sendo este o mês com maior número de dias chuvosos; na sequência está o mês de janeiro com 13 dias chuvosos. Os demais meses variam entre 5 a 11 dias com chuvas. 0 dia que concentrou o maior total pluviométrico foi 08 de junho, com $89,4 \mathrm{~mm}$, seguido por 11 de fevereiro e 16 de março, com 69,1 e 63,4 mm registrados, respectivamente.

0 ano de 1987, o segundo mais chuvoso da série, acumulou um total pluviométrico de 1774,4 $\mathrm{mm}$, concentrados nos meses de agosto, julho, maio e novembro. A média mensal para este ano foi de $147,8 \mathrm{~mm}$. Os meses com menor total pluviométrico foram junho e março (Fig. 6).

0 ano de 1987 teve 125 dias chuvosos, considerando aqueles com ocorrência superior a $1 \mathrm{~mm}$. Em agosto, o mês com maior total pluviométrico, houve a maior concentração mensal de dias chuvosos, totalizando 15 dias e em julho foram registrados 14 dias. Os dias com maior volume de chuvas foram 13 de maio $(60,8 \mathrm{~mm}), 11$ de janeiro $(53,4$ $\mathrm{mm})$ e 30 de agosto $(50,7 \mathrm{~mm})$.

O total pluviométrico de 2009 foi 1719,60 $\mathrm{mm}$, concentrados nos meses de setembro, novembro, agosto e janeiro. A média mensal de chuvas nesse ano foi de $143,3 \mathrm{~mm}$. Os meses com menores totais pluviométricos foram abril, junho e julho (esses últimos com praticamente o mesmo total, 57,1 e $57,2 \mathrm{~mm}$ ), quando choveu $89,4 \%$ (abril) e $80,5 \%$ (junho e julho) menos que no mês mais chuvoso (Fig. 7).

Em 2009 houve um total de 116 dias chuvosos; os meses com mais dias chuvosos foram setembro e novembro, ambos com 15 dias de chuva. 0 mês que apresentou o menor número de dias com chuvas foi abril, com 3 . Os dias chuvosos que concentraram os maiores volumes de chuva foram 10 de agosto, 08 e 14 de novembro, com 78,8 mm, $72,1 \mathrm{~mm}$ e $67,4 \mathrm{~mm}$, respectivamente.

Tendo em vista os dados obtidos observa-se que o mês de setembro está entre os quatro meses mais chuvosos em cinco dos seis anos com os 




Figura 5. Totais pluviométricos mensais do ano de 1972 (Fonte: Dados da Rede do INMET, 2013).

maiores volumes de chuva do período, seguido pelos meses de julho, agosto, novembro e janeiro, que figuram entre os meses mais chuvosos em três dos seis (Tab. 1).

Com base nos dados analisados, a ocorrência de eventos pluviométricos é constante, apresentando médias mensais elevadas nos meses mais chuvosos, e eventos concentrados recorrentes. Dessa forma a distribuição das chuvas no município é um fator capaz de gerar inundações e/ou alagamentos na área urbana, uma vez que ocorram em abundância e frequentemente.

Por essa razão, sabe-se que os eventos de inundação e/ou alagamento podem acontecer devido a vários dias de chuvas consecutivos ou a dias com totais pluviométricos elevados. Podem ocorrer ainda inundações e alagamentos causados pela ação conjunta desses dois eventos: prolongados e concentrados, conforme descrito anteriormente por Fujimoto (2001).

\subsection{Análise da cobertura vegetal, do uso da terra e das condições socioeconômicas}

0 período inicial do crescimento urbano de Porto Alegre foi marcado pelo avanço das edificações e do sistema viário na zona norte que, devido a instalação do porto e, em função de sua localização e infraestrutura, passou a ser a área mais procurada da cidade, tanto para moradia como para o desenvolvimento de atividades comerciais e industriais. No entanto, a dinâmica atual do espaço urbano de Porto Alegre apresenta dois vetores principais de crescimento: adensamento e verticalização nos bairros já consolidados das zonas leste e norte, enquanto na zona sul destaca-se a expansão horizontal periurbana onde ainda predomina a paisagem natural. Na última década, os empre- endimentos imobiliários lançados na zona sul para as classes sociais de média alta renda procuram vincular as amenidades naturais existentes (pôr do sol, vegetação, fauna, cursos d'água) às amenidades produzidas nos loteamentos e condomínios horizontais (segurança, conforto, equipamentos de lazer e recreação) (Moura et al., 2013).

Com isso, observa-se que o crescimento urbano vem se expandindo sobre essa área, passando a incorporar padrões diferenciados de uso do solo, transitando de uma área caracterizada pela predominância de patrimônio natural que propicia atividades de lazer e turismo, uso residencial rarefeito e atividades vinculadas ao setor primário (chácaras, sítios, haras), para uma área de ocupação mais densa, destacando-se o setor de serviços e de uso residencial nas tipologias de condomínios horizontais e loteamentos, além de vazios urbanos para fins especulativos.

A análise do mapeamento da Cobertura Vegetal e Uso da Terra (Fig. 8) permite observar a predominância de cobertura vegetal e as manchas de ocupação urbana. Dentre essa ocupação podemos diferenciar alguns tipos, como a ocupação urbana concentrada, que se refere aos edifícios, casas, ocupação espontânea e pavilhões, e a ocupação urbana dispersa que corresponde a áreas de ocupação predominantemente de casas com terrenos extensos e afastados entre si, o que permite a manutenção de área verde e uma baixa densidade de áreas construídas. Além disso, há as edificações rurais diversas como instalações rurais em geral, casas, galpões, silos, pocilgas, aviários e estábulos. A distribuição das categorias de cobertura vegetal e uso da terra seguem o expresso na tabela 2 .

No entanto, segundo levantamento mais recente de Almeida \& Strohaecker (2011) os valores da tabela 2 foram alterados para: agropecuário 


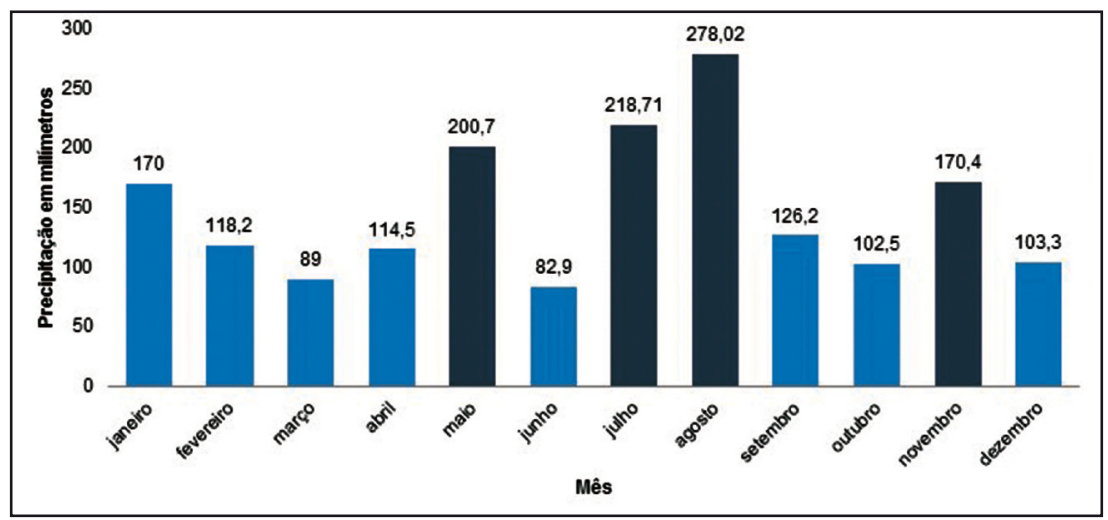

Figura 6. Totais pluviométricos mensais do ano de 1987 (Fonte: Dados da Rede do INMET, 2013).

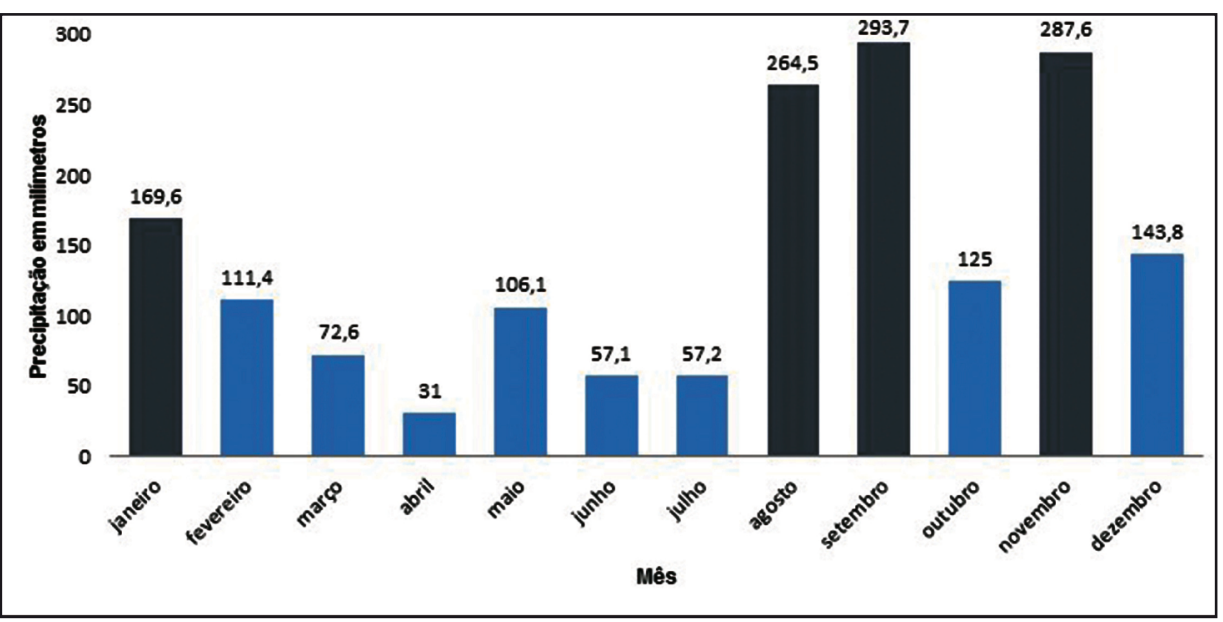

Figura 7. Totais pluviométricos mensais do ano de 2009 (Fonte: Dados da Rede do INMET, 2013).

Tabela 1. Meses com maiores índices pluviométricos entre os cinco anos com os maiores índices pluviométricos da série analisada, em ordem cronológica. Fonte: Dados da Rede do INMET, 2013.

\begin{tabular}{cccccc}
\hline $\mathbf{1 9 7 2}$ & $\mathbf{1 9 8 6}$ & $\mathbf{1 9 8 7}$ & $\mathbf{2 0 0 2}$ & $\mathbf{2 0 0 9}$ & $\mathbf{2 0 1 2}$ \\
\hline Junho & Novembro & Agosto & Julho & Setembro & Setembro \\
$(253,5 \mathrm{~mm})$ & $(283,4 \mathrm{~mm})$ & $(278,0 \mathrm{~mm})$ & $(186,6 \mathrm{~mm})$ & $(293,7 \mathrm{~mm})$ & $(273,7 \mathrm{~mm})$ \\
Agosto & Março & Julho & Junho & Novembro & Dezembro \\
$(239,2 \mathrm{~mm})$ & $(186,1 \mathrm{~mm})$ & $(218,7 \mathrm{~mm})$ & $(181,4 \mathrm{~mm})$ & $(287,6 \mathrm{~mm})$ & $(196,0 \mathrm{~mm})$ \\
Setembro & Maio & Maio & Outubro & Agosto & Janeiro \\
$(219,4 \mathrm{~mm})$ & $(164,4 \mathrm{~mm})$ & $(200,7 \mathrm{~mm})$ & $(177,6 \mathrm{~mm})$ & $(264,5 \mathrm{~mm})$ & $(166,0 \mathrm{~mm})$ \\
Janeiro & Setembro & Novembro & Setembro & Janeiro & Julho \\
$(215,4 \mathrm{~mm})$ & $(162,6 \mathrm{~mm})$ & $(170,4 \mathrm{~mm})$ & $(167,8 \mathrm{~mm})$ & $(169,6 \mathrm{~mm})$ & $(144,9 \mathrm{~mm})$ \\
\hline
\end{tabular}

23,11\% e vegetação florestal (39,70\%). Mesmo assim, ainda predominam, na bacia do arroio do Salso, espaços não urbanizados, ainda que existam alguns aglomerados urbanos consideráveis, tais como a Lomba do Pinheiro, bairro com muitas ocupações irregulares, localizado na área do divisor de águas com a bacia do Arroio Dilúvio, e a Restinga, bairro situado no setor central e que concentra mais da metade da população residente na área da bacia.

O mapa de uso da bacia hidrográfica do Arroio do Salso mostra a pouca ocupação da área, no entanto enfatiza que a ocupação existente é em padrão concentrado. Pode-se afirmar que a bacia hidrográfica possui aproximadamente $85 \%$ de sua área com cobertura vegetal e variados tipos de cultivos e $15 \%$ com intervenção humana, sendo que a grande maioria se refere à ocupação concentra- 
da predominantemente residencial (Moura et al., 2013).

A análise socioeconômica foi realizada a partir dos setores censitários do IBGE (2011), os quais foram selecionados visando contemplar a fisionomia espacial, dentro da área considerada de potencial à inundação, e buscando caracterizar os setores de ocupação concentrada e de ocupação dispersa. As áreas regulares e irregulares, tanto unifamiliar quanto multifamiliar referem-se basi- camente às edificações concentradas e, os condomínios fechados e loteamentos irregulares às edificações dispersas.

A partir da análise das formas de ocupação e das características socioeconômicas da população da bacia hidrográfica do Arroio do Salso constata-se que os dados socioeconômicos dos setores censitários selecionados se apresentaram semelhantes, indicando que a renda média de um a três salários mínimos e a escolaridade até cinco anos
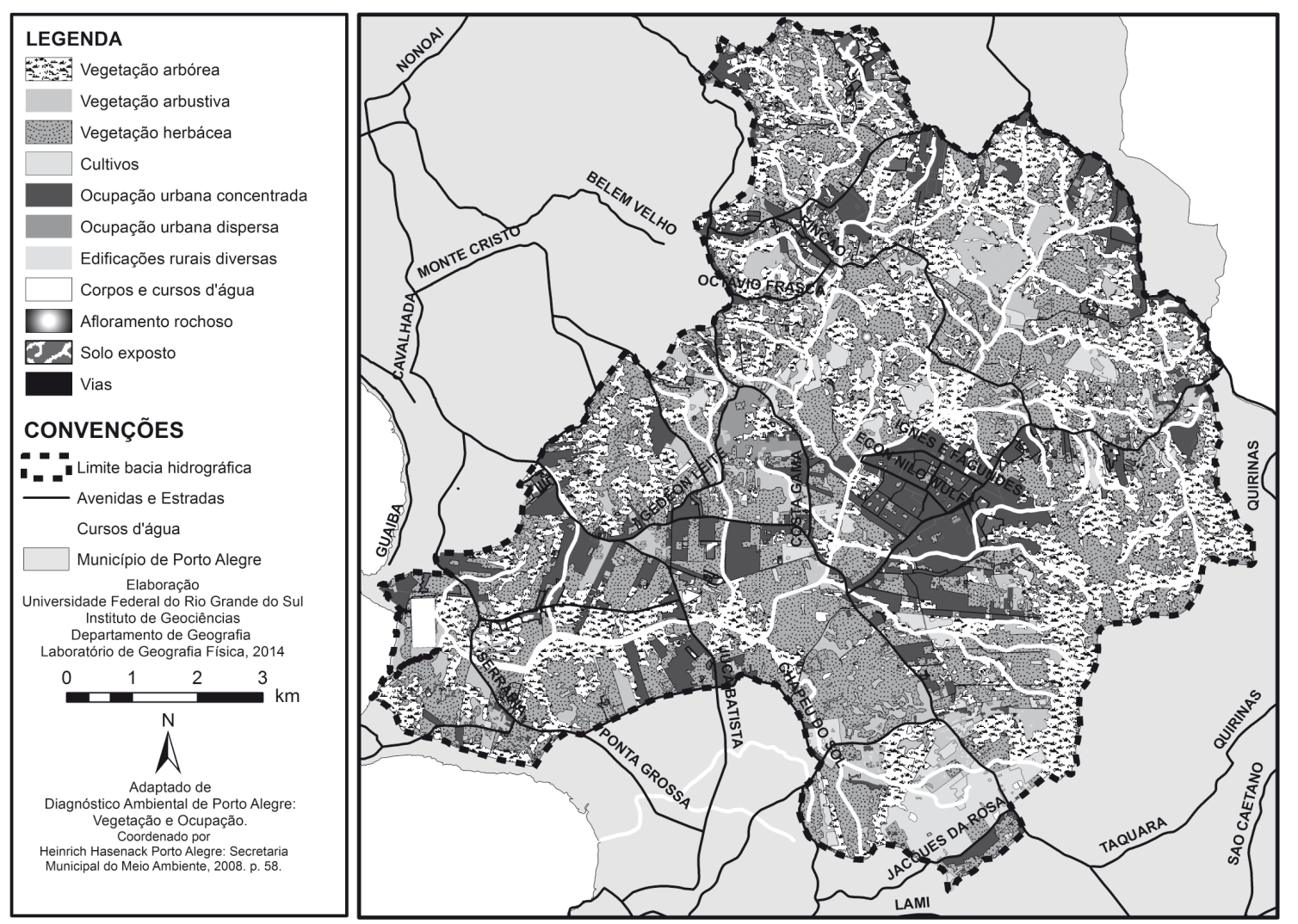

Figura 8. Mapa da cobertura vegetal e uso da terra da bacia hidrográfica do Arroio do Salso (adaptado de Hasenack, 2008, atualizado pelos autores em 2010).

Tabela 2. Distribuição das categorias de cobertura vegetal e uso da terra.

\begin{tabular}{lcc}
\hline \multicolumn{1}{c}{ Categoria } & Área $\mathbf{( k m}^{\mathbf{2}} \mathbf{\text { ) }}$ & Área em relação à Bacia (\%) \\
\hline Vegetação Arbórea & 30,66 & 33 \\
Vegetação Arbustiva & 6,04 & 6,5 \\
Vegetação Herbácea & 34,40 & 37 \\
Cultivo & 4,85 & 5 \\
Ocupação/Impermeabilização do solo & 12,36 & 13 \\
Ocupação Urbana Dispersa & 0,86 & 0,9 \\
Edificações Rurais Diversas & 0,92 & 1 \\
Solo Exposto & 1,40 & 1,5 \\
Afloramento Rochoso & 0,13 & 0,1 \\
Vias & 1,24 & 1,3 \\
Corpos e Cursos D'água & 0,68 & 0,7 \\
\hline
\end{tabular}


de estudo são os valores predominantes entre os responsáveis pelos domicílios pesquisados em todos os setores censitários. Em relação à infraestrutura, existe uma relativa igualdade, porém alguns setores apresentam condições deficitárias e estão associados à ocupação em moradias irregulares ou a atividades rurais (Tab. 3).

As comunidades que se localizam em setores da bacia hidrográfica considerada de alta susce- tibilidade à inundação apontaram deficiência na maioria dos seus domicílios com relação à infraestrutura. Por ocasião dos trabalhos de campo, alguns relatos da população local informaram que, muitos moradores dessas localidades, em períodos de chuvas mais prolongados, tiveram significativas perdas materiais e até mesmo humanas, demonstrando a grande vulnerabilidade dessas comunidades aos eventos de inundação.

Tabela 3. Infraestrutura dos setores censitários na bacia hidrográfica do Arroio do Salso. Fonte: Censo Demográfico do IBGE (2000).

\begin{tabular}{lccc}
\hline \multicolumn{1}{c}{ Setor Censitário (Bairro) } & $\begin{array}{c}\text { Rede geral de } \\
\text { esgoto (\%) }\end{array}$ & Fossa séptica (\%) & Outro (\%) \\
\hline 944 (Restinga) & 13,88 & 68,57 & 17,55 \\
942 (Restinga) & 18,04 & 42,03 & 39,93 \\
1190 (Hípica) & 2,00 & 75,92 & 22,08 \\
1187 (Hípica) & 5,37 & 94,63 & 0 \\
1189 (Hípica) & 15,04 & 78,95 & 6,01 \\
1227 (Aberta dos Morros) & 37,08 & 62,92 & 0 \\
1195 (Ponta Grossa) & 29,71 & 62,94 & 7,35 \\
1178 (Serraria) & 3,92 & 22,55 & 73,53 \\
1233 (Chapéu do Sol) & 29,55 & 35,23 & 35,22 \\
1237 (Chapéu do Sol) & 16,44 & 65,75 & 17,81 \\
\hline
\end{tabular}

\section{Conclusões}

Os resultados das análises granulométricas da cobertura superficial da bacia hidrográfica do Arroio do Salso permitiram confirmar a classificação feita previamente, através da análise de outros fatores que também influenciam os eventos de inundação (como a altimetria e declividade, por exemplo), a qual identificou quatro classes de suscetibilidade à inundação: baixa, média, alta e muito alta. As áreas classificadas como de baixa suscetibilidade foram as que apresentaram a fração granulométrica de sedimentos com significativa concentração de areias grossas e médias. A classe de muita alta suscetibilidade à inundação mostrou a maior e mais expressiva concentração de sedimentos muito finos, silte e argila. Os sedimentos mais finos são os de menor porosidade formando solos mal drenados. As áreas de baixas e médias suscetibilidades foram as que exibiram maior concentração de sedimentos mais grossos e os setores de alta e muita alta suscetibilidade apresentam grandes porcentagens de sedimentos mais finos. As áreas suscetíveis à inundação, analisadas na bacia hidrográfica do Arroio do Salso, são todas áreas planas relacionadas, predominantemente, às planícies flúvio-lagunares e patamares planos, porém a suscetibilidade é maior nas áreas topograficamente mais baixas com maior concentração de sedimentos finos (silte e argila).

0 aumento da urbanização causa transformações significativas no ambiente que, por muitas vezes, aceleram os processos geomorfológicos característicos de um determinado ambiente. Nesse sentido, a elaboração de indicadores ambientais em uma área em processo intenso de urbanização torna-se um documento importante na avaliação das suscetibilidades aos processos geomorfológicos, na medida em que, a partir desse instrumento, possam ser tomadas medidas preventivas e corretivas para o ordenamento territorial e/ou ambiental de um determinado território. Os efeitos da concentração e da densidade urbana, a desigualdade nas condições de acesso à infraestrutura pela população e as irregularidades urbanísticas, aumentam as consequências da inundação devido à vulnerabilidade social.

Agradecimentos: Ao Conselho de Desenvolvimento Científico e Tecnológico (CNPq), aos moradores dos bairros Restinga, Serraria e Ponta Grossa pela acolhida e pelos depoimentos.

\section{Referências}

Almeida, M.P. de \& Strohaecker, T.M. 2011. Análise das tendências de ordenamento territorial da Bacia do Arroio do Salso, Porto Alegre-RS. In: XXIII SALÃO 
DE INICIAÇÃO CIENTÍFICA DA UFRGS, 2011, Porto Alegre. Anais..., Porto Alegre, PROPESQ/UFRGS, v.1. 1CD-ROM.

Basso, L.A. \& Pizzato, F. 2011. A qualidade da água da bacia hidrográfica do arroio do Salso, Porto Alegre RS. In: SIMPÓSIO BRASILEIRO DE GEOGRAFIA FÍSICA APLICADA,14,Anais..., Dourados, UFGD, v.1., p.12. 1 CD-ROM.

BRASIL. Ministério da Agricultura e do Abastecimento. Instituto Nacional de Meteorologia. 1999. Manual de Observações Meteorológicas. 2 ed., Brasília, INMET.

BRASIL. Ministério das Cidades. Instituto de Pesquisas Tecnológicas. 2007. Mapeamento de Riscos em Encostas e Margem de Rios. Disponível em <http:// www.infraestrutura.salvador.ba.gov.br/. Acesso em: 04 jan. 2013.

Burkt, L.G. \& Fujimoto, N.S.V.M. 2009. A Cidade real supera a cidade legal? Um estudo sobre a bacia hidrográfica do Arroio do Salso, Porto Alegre/RS. In: ENCONTRO DE GEÓGRAFOS DA AMÉRICA LATINA, 12, Montevidéu, Anais...Montevidéu, v.1.1 CD-ROM.

Castells, M. 2000. A questão urbana. São Paulo, Paz e Terra, 590p.

CPTEC. Centro de Previsão de Tempo e Estudos Climáticos. 2014. El Niño e La Niña. Disponível em: http:// enos.cptec.inpe.br. Acesso em: jul. 2014.

DEP. Departamento de Esgotos Pluviais. Prefeitura Municipal de Porto Alegre. 2005. Plano Diretor de Drenagem Urbana de Porto Alegre. UFRGS/IPH. Volumes V, VI e IX.

Fujimoto, N.S.V.M. \& Dias, T.S. 2010. Estudo sobre a suscetibilidade à inundação do Setor Sul do município de Porto Alegre-RS: bacia hidrográfica do Arroio do

Man 572

Editores: Tatiana Silva da Silva \& Maria do Carmo Lima e Cunha.
Salso. In: SIMPÓSIO NACIONAL DE GEOMORFOLOGIA, 8, Recife, Anais...v.1, 15p. 1 CD-ROM.

Fujimoto, N.S.V.M. 2001. Análise ambiental urbana na área metropolitana de Porto Alegre - RS: sub-bacia hidrográfica do Arroio Dilúvio. São Paulo, 235p. Tese de doutorado. Programa de Pós-graduação em Geografia Física, Universidade de São Paulo.

Hasenack, H. 2008. Diagnóstico ambiental de Porto Alegre. Porto Alegre. Secretaria Municipal de Meio Ambiente. Porto Alegre, 87p.

IBGE. Instituto Brasileiro de Geografia e Estatística. 2004. Vocabulário básico de recursos minerais e meio ambiente. 2. ed., Rio de Janeiro, IBGE, 332p.

IBGE. Instituto Brasileiro de Geografia e Estatística. 2010. Censo Demográfico. Disponível em http:// www.ibge.gov.br. Acesso em: 12 jan. 2011.

INMET. Banco de Dados Meteorológicos para Ensino e Pesquisa. Dados da Rede do INMET. 2013. Disponível em: http://www.inmet.gov.br/portal/index. php?r=bdmep/bdmep. Acesso em: set. 2013.

Moura, N.S.V., Basso, L.A. \& Strohaecker, T.M. 2013. Indicadores Ambientais da Bacia Hidrográfica do Arroio do Salso, Município de Porto Alegre. Boletim Gaúcho de Geografia, 40(2): 236-253.

Tominaga, L.K. \& Santoro, J. Amaral, R. (Org.) 2012. Desastres Naturais: Conhecer para prevenir. Instituto Geológico/Secretaria do Meio Ambiente do Estado de São Paulo. Disponível em <http://www.igeologico.sp.gov.br/downloads/livros/DesastresNaturais. pdf>. Acesso em: jan. 2013.

Tucci, C.E.M. 2007. Inundações Urbanas. Porto Alegre, Associação Brasileira de Recursos Hídricos, 389p. 